\section{Temperature Effects on Interspecific Hybridization between Gladiolus Xgrandiflora and G. tristis}

\author{
Yasumasa Takatsu', Masakazu Kasumi, Toru Manabe, and \\ Mikio Hayashi \\ Plant BiotechnologyInstitute, Ibaraki Agricultural Center Iwama, Nishi-ibaraki, \\ Ibaraki, 319-0292, Japan
}

\author{
Eiichi Inoue, Wataru Marubashi, and Masaru Niwa \\ School of Agriculture, Ibaraki University, Ami, Inashiki, Ibaraki, 300-0393, \\ Japan
}

Additional index words. flow cytometry, gladiolus, interspecific hybrid, pollen, polyploidy

\begin{abstract}
Interspecific hybridization between a modern cultivar of Gladiolus xgrandiflora hort. $(2 n=60)$ and the wild species $G$. tristis $\mathrm{L}$. $(2 n=30)$ was made to introduce characteristics of the wild species into the cultivated one. Gladiolus xgrandiflora is a summer-flowering species, and $G$. tristis flowers in winter. The effect of storage temperature on pollen viability was tested, as long-term storage of pollen was necessary to facilitate crossing these two species. Pollen of $G$. tristis could be stored at $-20^{\circ} \mathrm{C}$ for $\approx 1$ year, and was more practical than storage at $-80^{\circ} \mathrm{C}$. Air temperature affected pollen tube growth, fertility, and fruit set in the cross between $G$. Xgrandiflora and $G$. tristis, and low temperatures $\left(15\right.$ to $\left.20^{\circ} \mathrm{C}\right)$ were best. The morphological data and flow cytometric analysis showed that the $F_{1}$ plants were hybrids between $G$. Xgrandiflora and $G$. tristis.
\end{abstract}

The genus Gladiolus is classified in the family Iridaceae, and the species are found in southern Africa, tropical Africa, Madagascar, and Eurasia. The number of species in the genus currently totals 255 (Goldblatt and Manning, 1998). Modern cultivars of $G$. $\times$ grandiflora, an important cut flower, were bred originally from only six species (Barnard, 1972), and considerable genetic potential exists for developing new kinds of gladiolus using wild species. As many wild species flower during winter and modern cultivars of $G$. $\times$ grandiflora flower in summer, storing the pollen is necessary to facilitate hybridization. In addition, flower abortion of $G$. $\times$ grandiflora occurs in the winter because of low light intensity, and the species is not coldresistant (Imanishi, 1989). Winter-flowering wild species are tolerant of low light intensity and cold temperatures. We attempted interspecific hybridization between $G$. $\times$ grandiflora and G. tristis in order to introduce some characters of the latter species, such as winter flowering, cold tolerance, and fragrance into the former hybrid. This cross combination has been reported in Israel with some miniature cultivars (Cohen and Barzilay, 1991). However, obtaining the interspecific hybrid

Received for publication 7 Apr. 2000. Accepted for publication 3 Aug. 2000. This work was supported in part by the grant for scientific research from the Ministry of Agriculture, Forestry and Fisheries. The cost of publishing this paper was defrayed in part by the payment of page charges. Under postal regulations, this paper therefore must be hereby marked advertisement solely to indicate this fact.

${ }^{1}$ To whom requests for reprints should be addressed. E-mail address: yasut@ post.agri.pref.ibaraki.jp without embryo rescue has been difficult in Japan (Takatsu et al., 1996). Pollen tube elongation and fertilization were observed, but the seed did not develop normally, suggesting that postfertilization barriers prevent interspecific crossing. The effect of environment on these barriers is not clear.

We describe here the long-term storage of pollen and the effect of air temperature on interspecific hybridization of gladiolus, and also provide an estimate of the ploidy level of $F_{1}$ progeny by flow cytometry in order to select

\section{Materials and Methods}

Plant materials and hybridization. Seeds of the diploid species Gladiolus tristis $(2 n=$ 30) were purchased from Silverhill Seeds Co. (Capetown, South Africa). This species was grown in a greenhouse at 12 to $25^{\circ} \mathrm{C}$ during winter and flowered at a low light intensity $\left(\approx 500\right.$ to $\left.900 \mu \mathrm{mol} \cdot \mathrm{m}^{-2} \cdot \mathrm{s}^{-1}\right)$. The flowers of this species have excellent fragrance. Pollen was collected and predried by the modified procedure of Koopowitz et al. (1984). Pollen collected from freshly dehisced stamens was dusted on to powder paper $\left(81 \mathrm{~cm}^{2}\right)$, predried in a desiccator for $24 \mathrm{~h}$ at room temperature, and then stored at -20 or $-80{ }^{\circ} \mathrm{C}$ for 1 year. Pollen viability was evaluated at $1,3,6$, and 12 months after the initiation of storage, as described by Heslop-Harrison and HeslopHarrison (1970), using fluorescein diacetate. In addition, the viability of pollen stored for 6 months was confirmed by self-pollination of $G$. tristis in a greenhouse.

Commercial gladiolus cv. Traveller of the tetraploid species $G$. × grandiflora $(2 n=60)$ hybrid plants. was potted in April and grown in an open field. Just before the flowering stage in July, potted plants were moved to growth chambers maintained at $15,20,25$, and $30{ }^{\circ} \mathrm{C}$, and were illuminated at $250 \mu \mathrm{mol} \cdot \mathrm{m}^{-2} \cdot \mathrm{s}^{-1}$ using a $16-\mathrm{h}$ photoperiod. Three potted plants were used for each treatment. Pollen of $G$. tristis stored for 6 months was used for interspecific crossing. 'Traveller' was self-pollinated under the same conditions as the control. Germination, elongation of pollen tube, and fertilization were confirmed by the methods described by Marubashi and Nakajima (1981) at 12 h, 24 h, $2 \mathrm{~d}, 3 \mathrm{~d}, 4 \mathrm{~d}$, and $5 \mathrm{~d}$ after pollination, using five florets. Fertility [(number of fertilized ovules/ total number of ovules $) \times 100$ ] was measured each time. The final rate of fruit set [(enlarged pods with matured seeds/total number of pods) $\times 100]$ was calculated at $30 \mathrm{~d}$ after pollination. Matured seeds were sowed immediately, and were grown as putative hybrid seedlings $\left(F_{1}\right.$ seedlings).

Confirmation of ploidy level of $F_{1}$ plants. The ploidy level of the $F_{1}$ seedling was determined by chromosome counting and flow cytometry. Three root tips were collected and immersed in $3 \mathrm{~mm} 8$-hydroxyquinoline for $6 \mathrm{~h}$ at $20^{\circ} \mathrm{C}$, and were fixed in 3 ethanol : 1 acetic acid (by volume) for $24 \mathrm{~h}$ at room temperature. They were then hydrolyzed for 8 min in $1 \mathrm{~N} \mathrm{HCl}$ at $60^{\circ} \mathrm{C}$, stained with Schiff's reagent (Wako, Osaka, Japan) for $2 \mathrm{~h}$, and were squashed with a cover slip for chromosome counting. Content of DNA was evaluated by flow cytometry of $G$. × grandiflora 'Traveller', G. tristis, and $\mathrm{F}_{1}$ seedlings, and we estimated the ploidy levels. For flow cytometric analysis, we collected $25-\mathrm{mm}^{2}$ portions of the blade of young leaves from these plants. These portions were chopped in $0.5 \mathrm{~mL}$ nuclear extraction buffer (solution A of the High Resolution Kit for PlantDNA; Partec, Münster, Germany). After filtration through a $30-\mu \mathrm{m}$ nylon sieve, $2 \mathrm{~mL}$ of staining solution containing the dye 4,6-diamidino-2-phenylindole-2 $\mathrm{HCl}$ (DAPI, solution B of the Kit) was added. The analysis was made using a PA flow cytometer (Partec), in three independent trials.

\section{Results and Discussion}

Long-term storage of pollen. The viability of pollen of $G$. tristis stored at -20 and $-80^{\circ} \mathrm{C}$ for 6 months was $51.6 \%$ and $80.8 \%$, respectively (Fig. 1). This pollen was functional in controlled hybridizations; $36.6 \pm 5.8$ and 37.6 \pm 2.5 seeds per pod were produced using pollen stored at -20 and $-80^{\circ} \mathrm{C}$, respectively, with no significant difference between treatments. Koopowitz et al. (1984) reported that pollen of G. tristis can be stored at $-40^{\circ} \mathrm{C}$ and that stored pollen is viable for 1 year. Our results agree with this study. The viability of pollen stored for 1 year was $27.6 \%$ and $67.2 \%$ at -20 and $-80{ }^{\circ} \mathrm{C}$, respectively. Usually, we collect pollen of $G$. tristis in the winter and store it for 6 months before using in hybridizations in the summer (Takatsu et al., unpublished data). These observations suggest that storage of pollen at $-20{ }^{\circ} \mathrm{C}$ is appropriate to maintain its viability for practical use, and is 
more convenient than storage at -40 and -80 ${ }^{\circ} \mathrm{C}$, as we can use a standard freezer for storage.

Effect of air temperature on success of interspecific crosses. Air temperature had a marked effect on fertility in controlled crosses (Fig. 2). At $20^{\circ} \mathrm{C}$, the pollen tube elongated very rapidly, fertilization was accomplished $12 \mathrm{~h}$ postpollination, and the fertility increased to $89.9 \% 5 \mathrm{~d}$ postpollination. At 15 and $25^{\circ} \mathrm{C}$, pollen tube elongation slowed, fertilization was first observed 3 and $1 \mathrm{~d}$ postpollination, and the final fertility increased to only $76.4 \%$ and $73.2 \%$, respectively. At $30^{\circ} \mathrm{C}$, pollen tube elongation was inhibited more and the final fertility was very low $(1.4 \%)$. The final rate of fruit set decreased from $73.1 \%$ to $0.0 \%$ as the temperature increased, but pollen tube growth and fruit set were found even at $30^{\circ} \mathrm{C}$ following self-pollination of 'Traveller' (Fig. 3). Crossing barriers frequently occur in interspecific crosses, but sexual barriers preventing crossing have been separated into pre- and postfertilization barriers (Van Tuyl, 1997). In this study, the results of self-pollination of 'Traveller' indicated that female fertility is good at $30^{\circ} \mathrm{C}$. Although fertilization was observed in interspecific crossing at $30{ }^{\circ} \mathrm{C}$, no fruit set was obtained. The best temperature for fertilization was $20^{\circ} \mathrm{C}$ (Fig. 2), but that for fruit set was $15^{\circ} \mathrm{C}$ (Fig. 3). These results show that postfertilization barriers inhibit interspecific hybridization between 'Traveller' and $G$. tristis, and may explain the failure to obtain hybrids without embryo rescue (Takatsu et al., 1996). Our results suggest that lower air temperatures (15 to $20^{\circ} \mathrm{C}$ ) increase fertility and may be appropriate to help overcome postfertilization barriers when hybridizing $G$. $\times$ grandiflora and G. tristis. Humidity and air temperature is very high (over $30^{\circ} \mathrm{C}$ ) in summer in Japan; thus, crossing in autumn is preferred if the flowering time can be controlled.

Production of interspecific hybrids. Since the first report by Heller (1973), flow cytometry has been used in plant science (Bergounioux et al., 1992; Galbraith, 1989). It is especially useful for easy, rapid, and accurate determination of ploidy level. Table 1 summarizes the results of chromosome counting and flow cytometric analysis. The chromosome number correlated with fluorescence intensity $(r=$ $\left.0.98^{* *}\right)$ in $G$. × grandiflora and G. tristis, and the diploid species $G$. tristis showed one-half the fluorescence intensity of the tetraploid species $G$. × grandiflora. This suggests that estimating the ploidy levels of hybrids between these two species by flow cytometry is possible.

Eighty-four seeds matured completely, and 28 seedlings $(33.3 \%)$ grew after sowing, but only 18 plants $(21.4 \%)$ flowered normally. $F_{1}$ seedlings obtained by interspecific hybridization showed intermediate value of fluorescence intensity between $G$. $\times$ grandiflora and $G$. tristis by flow cytometric analysis (Table 1). Table 2 lists descriptive data for the $F_{1}$ plants, whose chromosome number was 45 . Most $F_{1}$ plants exhibited some degree of male sterility. $F_{1}$ plants had intermediate floret num-

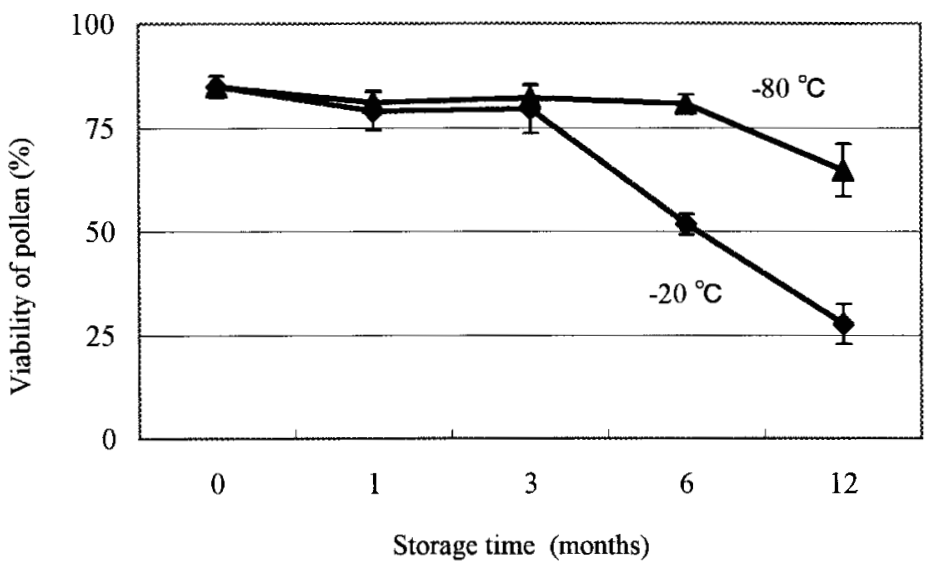

Fig.1. Viability of pollen stored at -20 and $-80^{\circ} \mathrm{C}$ was measured at $0,1,3,6$, and 12 months after storage. Pollen of $G$. tristis was predried at room temperature for $24 \mathrm{~h}$ prior to storage. Viability of pollen was evaluated using fluorescein diacetate, as described by Heslop-Harrison and Heslop-Harrison (1970), in three independent trials at each time. Vertical bars indicate $\operatorname{SD}(n=3)$.

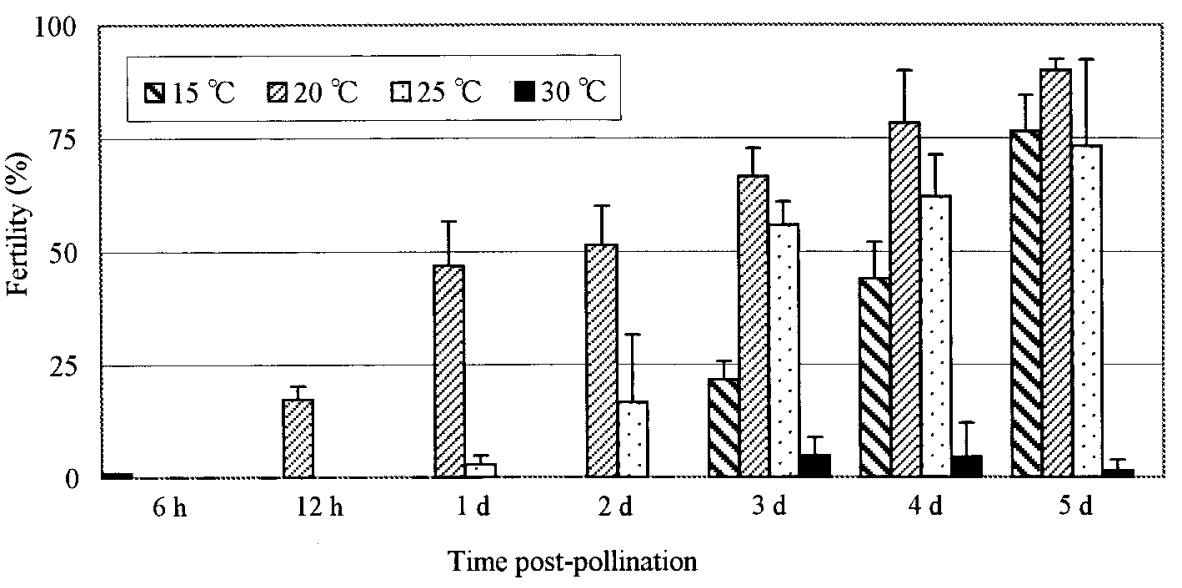

Fig. 2. Effects of temperature and time on percentage of fertility [(number of fertilized ovules/total number of ovules $) \times 100$ ] following pollination of $G$. $\times$ grandiflora flowers with $G$. tristis pollen. Fertilization of ovules was confirmed by the methods described by Marubashi and Nakajima (1981). Vertical bars indicate $\mathrm{SD}(n=5)$.

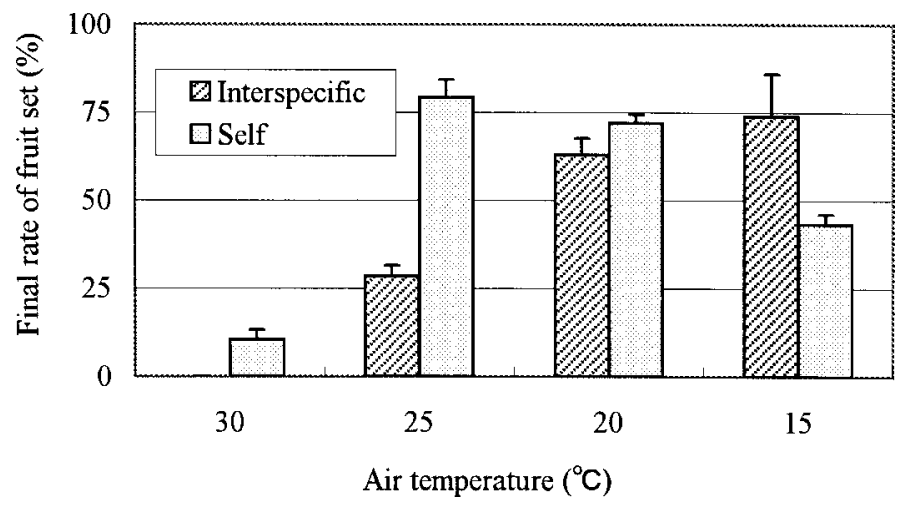

Fig. 3. Final rate of fruit set [(number of enlarged pod with matured seeds/ total number of pod) $\times 100]$ at $15,20,25$, and $30^{\circ} \mathrm{C}$, in interspecific hybridization between $G$. × grandiflora 'Traveller' and G. tristis (Interspecific), and in self-pollination of 'Traveller' (Self). Fruit set was confirmed at $30 \mathrm{~d}$ after pollination. Vertical bars indicate $\operatorname{SD}(n=5)$. 
Table 1. Comparison of flow cytometric analysis, chromosome number determination and estimated ploidy level in a $\mathrm{F}_{1}$ hybrid between $G$. $\times$ grandiflora and $G$. tristis.

\begin{tabular}{lccc}
\hline Species & $\begin{array}{c}\text { Fluorescence } \\
\text { intensity }^{\mathrm{z}}\end{array}$ & $\begin{array}{c}\text { Chromosome } \\
\text { number }^{\mathrm{y}}\end{array}$ & $\begin{array}{c}\text { Estimated } \\
\text { ploidy levels }^{\mathrm{x}}\end{array}$ \\
\hline G. tristis & $138.8 \pm 3.7^{\mathrm{w}}$ & 30 & $2 \times$ \\
$\mathrm{F}_{1}$ seedling & $226.7 \pm 13.6$ & 45 & $3 \times$ \\
G. $\times$ grandiflora & $286.4 \pm 2.1$ & 60 & $4 \times$ \\
\hline
\end{tabular}

${ }^{\mathrm{z}}$ Fluorescence intensity indicates a relative value of amount of DNA. Within one sample, a minimum of 10,000 particles (total count) were analyzed in three independent trials.

${ }^{y}$ Chromosome numbers of $G$. tristis and $G$. $\times$ grandiflora have been published. That of $\mathrm{F}_{1}$ seedling was confirmed by chromosome counting.

$\mathrm{x} 2 \times, 3 \times$, and $4 \times$ indicate diploid, triploid, and tetraploid, respectively.

${ }^{\mathrm{w}}$ Mean $\pm \mathrm{SD}(n=3)$.

Table 2. Some characteristics of G. × grandiflora 'Traveller', G. tristis, and $\mathrm{F}_{1}$ hybrid.

\begin{tabular}{|c|c|c|c|c|c|c|c|}
\hline \multirow[b]{2}{*}{ Strains } & \multirow[b]{2}{*}{$\begin{array}{c}\text { Petal } \\
\text { Main color }\end{array}$} & \multicolumn{2}{|c|}{ Florets } & \multicolumn{2}{|c|}{ Leaves } & \multirow[b]{2}{*}{$\begin{array}{c}\text { Total } \\
\text { height }^{\mathrm{y}}(\mathrm{cm})\end{array}$} & \multirow[b]{2}{*}{$\begin{array}{c}\text { Flowering } \\
\text { time }\end{array}$} \\
\hline & & $\begin{array}{l}\text { No./ } \\
\text { stalk }^{2}\end{array}$ & $\begin{array}{l}\text { Width } \\
(\mathrm{mm})\end{array}$ & Total & $\begin{array}{l}\text { Width } \\
(\mathrm{mm})\end{array}$ & & \\
\hline Traveller & Pinkish white & $17.0 \pm 1.0$ & $10.8 \pm 0.3$ & $9.3 \pm 0.6$ & $3.2 \pm 0.3$ & $138.6 \pm 4.9$ & June to Nov. \\
\hline G. tristis & Pinkish white & $3.6 \pm 0.6$ & $3.3 \pm 0.6$ & $3.6 \pm 0.6$ & $0.6 \pm 0.2$ & $90.3 \pm 4.5$ & Feb. to Apr. \\
\hline $\mathrm{F}_{1}$ hybrid & $\begin{array}{l}\text { Pinkish white } \\
\text { Vivid pink } \\
\text { Dark pink } \\
\text { Light pink, etc. }\end{array}$ & $10.4 \pm 2.4$ & $6.2 \pm 0.8$ & $6.4 \pm 1.1$ & $1.6 \pm 0.3$ & $84.8 \pm 8.3$ & Mar. to Oct. \\
\hline
\end{tabular}

${ }^{y}$ Flowering stem length in G. tristis.

bers, floret width, leaf number, and leaf width. The total height was measured as the spike length in $G$. × grandiflora and hybrids, but $G$. tristis has a long flowering stem instead of a spike, indicating that the $F_{1}$ plants were hybrids of these parents. These plants showed a variety of flower colors [vivid pink, light pink, and light pink (with or without) a white stripe], but they lacked fragrance.

\section{Literature Cited}

Barnard, T.T. 1972. On hybrids and hybridization. In: G.J. Lewis, A.A. Obermeyer, and T.T. Barnard. Gladiolus, a revision of the South African species. J.S. Afr. Bot. 10 Suppl.:304-310.

Bergounioux, C., S.C. Brown, and P.X. Petit. 1992. Flow cytometry and plant protoplast cell biology. Physiol. Plant. 85:374-386.

Cohen, A. and A. Barzilay. 1991. Miniature gladiolus cultivars bred for winter flowering. HortScience 26:216-218.

Galbraith, D.W. 1989. Analysis of higher plants by flow cytometry and cell sorting. Intl. Rev. Cytol. 116:165-228.

Goldblatt, P. and J. Manning. 1998. Gladiolus in southern Africa. Fernwood Press, Vleaberg, S. Africa.

Heller,F.O. 1973. DNS-Bestimmung an Keimwurzeln von Viciafaba L. mit Hilfe der Impulsphotometrie. Ber. Dtsch. Bot. Ges. 36:437-441.

Heslop-Harrison, J. and Y. Heslop-Harrison. 1970. Evaluation of pollen viability by enzymatically induced fluorescence; intracellular hydrolysis of fluorescein diacetate. Stain Technol.45:115-120.

Imanishi, H. 1989. Gladiolus (in Japanese), p. 10771080. In: T. Matsuo (ed.). Collected data of plant genetic resources. Kodansha Scientific, Tokyo.

Koopowitz, H., R. Voss and C. O'Neil. 1984. Longterm storage of gladiolus pollen. HortScience 19:513-514.

Marubashi, W. and T. Nakajima. 1981. Pollen tube behavior in the ovary of Nicotiana tabacum L. Jpn. J. Breed. 31:133-140.

Takatsu, Y., E. Inoue, M. Kasumi, H. Tomotsune, and F. Sakuma. 1996. Interspecific and intergeneric crossing in gladiolus: Embryo rescue by ovule culture and analysis of RAPD pattern in hybrids. Breed. Sci. 46 (Suppl. 2):237. (Abstr. in Japanese.)

Van Tuyl, J.M. 1997. Interspecific hybridization of flower bulbs: A review. Acta Hort. 430:465476. 